\title{
Contrasting Obesity-Related Beliefs and Behaviors among West and East Coast Chinese Americans
}

\author{
Doreen Liou* , Kathleen D. Bauer \\ Department of Nutrition and Food Studies, Montclair State University, Montclair, New Jersey, USA \\ *Corresponding author: lioud@montclair.edu
}

\begin{abstract}
The obesity epidemic is a worldwide health epidemic. The purpose of this research is to ascertain obesity risk reduction behaviors and their psychosocial determinants in Chinese Americans. This study used a crosssectional survey design with a convenience sample of 203 participants in Los Angeles, compared with a New York sample $(n=447)$ of individuals between 18 to 60 . Obesity risk reduction behaviors were assessed and psychosocial constructs from the Theory of Planned Behavior and Health Belief Model were measured. T-test comparisons and multiple regression analyses were conducted to determine the psychosocial predictors of obesity risk reduction behavior. In the LA sample, regression analysis indicated that $38.7 \%$ of the variance in behavior was accounted by self-efficacy and attitude. Among NY participants, self-efficacy, intention, and attitude contributed to $47 \%$ of the variance of behavior. T-test comparisons indicated a higher frequency of healthy behaviors such as consuming nutritious snacks and the recommended daily servings of fruits and whole grains among LA participants. In contrast, the NY sample perceived greater barriers in performing obesity risk reduction behaviors such as the impact of the physical environment on food choices. Nutrition professionals designing interventions with Chinese Americans need to assess their efficacy, intentions, and attitudinal predispositions in performing obesity risk reduction behaviors. A greater emphasis should be placed on addressing barriers of healthy eating when working with Chinese Americans living in the New York metropolitan area.
\end{abstract}

\section{Keywords: obesity risk reduction behavior, Psychosocial theories, Chinese Americans}

Cite This Article: Doreen Liou, and Kathleen D. Bauer, "Contrasting Obesity-Related Beliefs and Behaviors among West and East Coast Chinese Americans." Journal of Food and Nutrition Research, vol. 6, no. 3 (2018): 168-175. doi: 10.12691/jfnr-6-3-5.

\section{Introduction}

The obesity epidemic is a critical global health challenge affecting all population groups regardless of age, gender, ethnicity, or socioeconomic status [1]. Although obesity rates among Asian Americans are lower than other racial groups in the United States (U.S.) [2], $11.6 \%$ as compared to $33.9 \%$ among adults over 20 years of age in the general population, weight gains are an issue for this group. A generational analysis of Chinese Americans indicates increasing rates of overweight and obesity among successive generations [3-8]. In particular, weight issues are increasingly found among younger Asians born in the United States [6]. Acculturation to an American diet and lifestyle increases risk of obesity for all immigrants including Chinese Americans. U.S. born Asians are 3-4 times more likely to be obese than foreign-born [7], and length of U.S. residence is positively related to weight gain [8].

Body mass index (BMI, $\mathrm{kg} / \mathrm{m}^{2}$ ) is used to classify individuals as underweight, overweight, and obese. A body mass index of 25 to 29.9 signifies overweight and 30 and above designates various levels of obesity [9]. Asians tend to accumulate excess body fat in the abdominal region thereby increasing risk for weight-related health problems such as metabolic syndrome, cardiovascular disease, inflammation, and hypertension [10,11]. After adjusting for age and gender, Asians are 30 to 50\% more likely to develop type 2 diabetes at lower body mass index levels than non-Hispanic whites $[7,12]$. Therefore, the World Health Organization (WHO) provides lower cut-off values for designating overweight and obese Asians, $\geq 23$ and $\geq 27.5$ respectively [13]. However, the WHO recommends using traditional cut-off values when comparing population groups.

Asian Americans are one of the fastest growing population groups in the U.S. comprising approximately $5.4 \%$ of the U.S. population with a predicted increase to $9.3 \%$ by 2060 [14]. Chinese Americans are the largest Asian subgroup. Los Angeles County houses the largest population of Asian Americans including Chinese Americans than any other county in the United States, and the Asian community continues to grow at a rate $20 \%$ faster than any other racial group [15].

\subsection{Theoretical Framework}

Individuals' beliefs and motivations for adopting health behaviors to mitigate disease outcomes can be expressed in various frameworks and theories stemming from social 
psychology. The Health Belief Model (HBM) postulates that an individual is likely to adopt an action to prevent a specific disease or condition, if perceptions of susceptibility and severity exist [16]. In addition, a person would need to perceive specific benefits in taking actions that would effectively prevent or cure the disease and perceive no major barriers impeding the health action. Self-efficacy, an individual's belief in the ability to perform a specific task by overcoming barriers, is also included in the model [17].

Ajzen's [18] Theory of Planned Behavior (TPB) asserts that behavioral intention is highly predictive of an individual's behavior, of which intention is derived from three components: (1) an individual's attitude toward an action; (2) subjective norm; and (3) perceived behavioral control (PBC). Attitude encompasses an individual's behavioral beliefs as well as one's evaluation of the outcome. Subjective norm is referred to perceived social pressure to perform an action based on the opinion of any given referent (normative beliefs) and weighted by the motivation to comply with the wishes of the referent. Perceived behavioral control is defined as the perceived degree of control over enacting a specific action.

Considering the predicted population expansion of Chinese Americans coupled with the detrimental health risks associated with excessive weight gain, researchers have a clear need to investigate weight-related lifestyle behaviors and beliefs within this population group. The purpose of this study was to ascertain obesity risk reduction behaviors and their psychosocial determinants among a convenience sample of Chinese Americans residing in Los Angeles (LA) County, California and to compare the results to Chinese Americans living in the New York (NY) metropolitan area. A similar study of New York area Chinese Americans was previously completed and published by the same researchers [19]. To our knowledge, this breakthrough study marks the first West and East Coast comparative analysis of obesityrelated beliefs and behaviors among Chinese Americans.

\section{Methods}

\subsection{Participants}

This study consisted of a cross-sectional survey design comprised of a convenience sample of free-living U.S.-born and foreign-born Chinese Americans living in Los Angeles County, California, between the ages of 18 to 60 years. Specific areas were targeted in LA County with high percentages of Chinese Americans such as San Gabriel, Arcadia, and Torrance. Various Chinese American associations were solicited for participation including educational institutions, churches, and cultural centers located in LA County providing a diverse range of socioeconomic status and educational backgrounds. These organizations were selected based on their high concentration of individuals who met the research criteria. The researchers aimed for a minimum sample size of 200, to ensure statistically significant outcomes per number of variables examined. A raffle drawing for \$25 and \$50 gift cards was offered as an incentive for participation. All volunteer participants received hard copies of the survey instrument, informed consent form, and a self-addressed, stamped envelope. An option to complete an online version of the survey was also available. A New Jersey state university Institutional Review Board granted approval to conduct the study.

\subsection{Data Collection}

Data collection of the LA study took place from January 2017 to June 2017 and were systematically compared with a similar study of 447 Chinese Americans residing in the NY metropolitan area $[19,20]$. Both studies were conducted by the same researchers using a survey instrument that the researchers developed in 2012.

\subsubsection{Measures}

The questionnaire contained 140 questions measuring obesity risk reduction behaviors, psychosocial variables, and demographic factors (Table 1). The respondents took an average of 20 minutes to complete the surveys. Nineteen questions measured five domains of obesity risk reduction behaviors over the previous month using a scale of 1 to 4 (never/rarely to always/usually). The five behavioral domains in this category included the following contexts: food (9 items), eating behavior (4 items), physical activity (2 items), psychological context (2 items), and knowledge awareness (2 items). These domains reflected findings from the literature and items were amended for their applicability based on qualitative research for Chinese Americans [21,22].

Table 1. Examples of Questionnaire Items

\begin{tabular}{|c|c|}
\hline \multirow{2}{*}{\multicolumn{2}{|c|}{$\begin{array}{l}\quad \text { Constructs } \\
\text { Psychosocial Statements - } \\
\text { Health Belief Model }\end{array}$}} \\
\hline & \\
\hline Perceived benefits & $\begin{array}{l}\text { As long as I eat a lot of fruits and vegetables, } \\
\text { my chances of becoming obese will be very } \\
\text { low. }\end{array}$ \\
\hline Perceived barriers & $\begin{array}{l}\text { I find it hard to prepare home-cooked meals } \\
\text { due to lack of time. }\end{array}$ \\
\hline Perceived susceptibility & $\begin{array}{l}\text { I may develop obesity because of my } \\
\text { sedentary lifestyle. }\end{array}$ \\
\hline Perceived severity & $\begin{array}{l}\text { If I become obese, my career will be } \\
\text { jeopardized. }\end{array}$ \\
\hline Cues to Action & $\begin{array}{l}\text { Health segments on television or radio are a } \\
\text { reminder that I should watch my weight. }\end{array}$ \\
\hline Self-Efficacy & $\begin{array}{l}\text { How confident are you in consuming small } \\
\text { portion sizes of food? }\end{array}$ \\
\hline \multicolumn{2}{|l|}{ Psychosocial Statements - } \\
\hline \multicolumn{2}{|c|}{ Theory of Planned Behavior } \\
\hline Behavioral intention & $\begin{array}{l}\text { During the upcoming week, I plan to choose } \\
\text { smaller portion sizes. }\end{array}$ \\
\hline Attitude & $\begin{array}{l}\text { Choosing steamed foods instead of fried } \\
\text { foods is.... } \\
\text { (Favorable vs. Unfavorable) }\end{array}$ \\
\hline Normative beliefs & $\begin{array}{l}\text { In general, how much influence does your } \\
\text { friends have on your food choices? }\end{array}$ \\
\hline Motivation to comply & $\begin{array}{l}\text { If my friends gave advice on dietary matters, } \\
\text { I (would - would not) follow it. }\end{array}$ \\
\hline $\begin{array}{l}\text { Perceived } \\
\text { behavioral control }\end{array}$ & I am in total control of my weight. \\
\hline
\end{tabular}




\section{Obesity Risk Reduction Behaviors}

Eating context context awareness context

- Monitored my body weight?

- Learned about obesity risk and prevention (e.g.: attending seminars, reading health articles, watching health programs on TV)?

Physical activity - Exercised at least 30 minutes, on 3 to 5 days context per week (e.g. walking, biking)?

- Engaged in at least 1 physically active leisure activity?

Regarding TPB constructs, 12 items addressed attitude towards a given behavior using a 7-point Likert-type scale. For example, "Using large amounts of cooking oils or fat in preparing meals is... ('favorable' to 'unfavorable'). Eleven items using a 7-point scale ('extremely unlikely' to 'extremely likely') measured intention to engage in obesity prevention behaviors in the upcoming week. An example would be "During the next week, I plan to choose small portion sizes of food." A 7-point scale ('not at all' to 'very much') was used to evaluate 11 subjective norm questions. This construct entailed normative beliefs ("In general, how much influence does your spouse or partner have on your food choices?") and motivation to comply ("If my spouse or partner tells me to choose healthy foods, (I would-I would not)”. Lastly, 3 perceived behavioral control statements were measured such as "I am in total control of my weight."

As for the HBM, 6 items measured perceived susceptibility and severity of developing obesity. For example, "I am concerned that I may develop obesity as I get older" was used to measure perceived susceptibility. "If I become obese, my career will be jeopardized" is an example of perceived severity. A 5-point scales ('strongly agree' to 'strongly disagree') rated all HBM variables. Five items measured perceived benefits based on perceptions that exercising regularly, eating fruits and vegetables, and limiting high-calorie soft drinks will lower one's likelihood of becoming obese. Perceived barriers (8 items) included the perceptions that healthy meals are difficult to prepare due to cost, insufficient time, and inconvenience. Five items measured cues to action such as "When I see other people eating healthfully, I am inclined to choose healthful foods.” Lastly, participants indicated their self-efficacy ( 9 items) or confidence to engage in various obesity risk reduction behaviors such as incorporating small portion sizes of food. A 5-point scale ('extremely confident' to 'not at all confident') rated the self-efficacy items.

Demographic factors included birthplace, gender, age, education level, marital and working status, income, and self-reported height and weight. In addition, participants identified self-reported physical activity levels ('sedentary' to 'heavy activity'), and overall quality of their health ('excellent' to 'poor').

\subsection{Questionnaire Validity and Reliability}

Table 2. Cronbach's Alpha Internal Consistency Coefficients for Scales Measuring Psychosocial Variables and Obesity Risk Reduction Behaviors

\begin{tabular}{|c|c|c|}
\hline Psychosocial Factors & $\begin{array}{l}\text { Number of } \\
\text { Items }\end{array}$ & $\begin{array}{l}\text { Cronbach's } \\
\text { Alpha } \\
\text { Coefficients } \\
(n=650)\end{array}$ \\
\hline \multicolumn{3}{|l|}{ Theory of Planned Behavior } \\
\hline Behavioral Intention & 11 & 0.9 \\
\hline Attitude & 12 & 0.9 \\
\hline Normative Beliefs & 4 & 0.7 \\
\hline Motivation to Comply & 7 & 0.8 \\
\hline $\begin{array}{l}\text { Perceived Behavioral } \\
\text { Control }\end{array}$ & 3 & 0.7 \\
\hline \multicolumn{3}{|l|}{ Health Belief Model } \\
\hline Perceived Benefits & 5 & 0.7 \\
\hline Perceived Barriers & 8 & 0.7 \\
\hline Perceived Susceptibility & 3 & 0.7 \\
\hline Perceived Severity & 3 & 0.7 \\
\hline Cues to Action & 5 & 0.7 \\
\hline Self- Efficacy & 9 & 0.8 \\
\hline \multicolumn{3}{|l|}{$\begin{array}{l}\text { Obesity Risk Reduction } \\
\text { Behaviors }\end{array}$} \\
\hline $\begin{array}{l}\text { Eating Context } \\
\text { Food Context } \\
\text { Psychological Context } \\
\text { Knowledge Awareness } \\
\text { Physical Activity }\end{array}$ & 19 & 0.8 \\
\hline
\end{tabular}

A pilot study of 30 Chinese Americans evaluated the clarity and meaning of questionnaire items. Consistency of their responses with the researchers' intended meaning of the survey questions provided confirmation of face validity. An expert panel of nutrition and behavioral science researchers reviewed the contents of the 
instrument for accurate reflection of constructs. An exploratory factor analysis of principle variables established construct validity. The entire scale produced 9 distinct factors accounting for $62.3 \%$ of the variance in responses. After additional factor analysis for each subscale, 6 items had a factor loading of less than 0.40 and were deleted from the scale [23].

The subscale of obesity risk reduction behavior yielded 5 distinct factors accounting for $60.3 \%$ of the variance in responses. These distinct factors corresponded conceptually to the 5 contexts of obesity risk reduction behaviors: food, eating behavior, physical activity, psychological context, and knowledge/awareness. A Cronbach's alpha internal consistency assessment measured reliability. The Cronbach's alpha coefficients of the behavioral variables $(0.8)$ and all the psychosocial variables were at or above 0.70 , reflecting good psychometric properties (Table 2). Further details of the instrument's validity and reliability can be found in a previously published study [19].

\subsection{Analysis}

Stepwise multiple regression analyses determined obesity risk reduction behaviors that were explained by TPB and HBM variables. TPB variables included behavioral intention, attitude, normative beliefs, motivation to comply, perceived behavioral control. HBM variables incorporated perceived susceptibility, perceived severity, perceived benefits, perceived barriers, cues to action, and self-efficacy. Standardized multiple regression coefficients $(\beta)$ enabled assessment of the relative importance of each psychosocial variable in explaining behavioral intention and obesity risk reduction behaviors. Frequency distributions described behavioral, psychosocial, and demographic data. T-test comparisons of behavioral, psychosocial, and demographic factors between the LA and NY samples were conducted. Self-reported weights were used to group BMI categories. These included underweight (BMI $<18.5)$, normal $(18.5 \leq \mathrm{BMI}<25)$, overweight $(25 \leq \mathrm{BMI}<30)$, and obese (BMI $\geq 30)$. In addition, Asian WHO BMI categories were assessed [13]. Statistical Package for Social Sciences (SPSS), version 23.0 was used to analyze the data. For all data analyses, the significance level was set at 0.05 . Ten returned surveys with missing data were discarded.

\section{Results}

\subsection{Demographic Data}

Approximately 350 surveys were distributed to individuals from diverse cultural, religious, and academic institutions in Los Angeles County, of which 203 questionnaires were returned, resulting in a $58 \%$ response rate. As shown in Table 3 , the mean age of the study participants was 38.1 years old $(S D=12.8)$. Sixty-eight percent of the entire sample was female, $49 \%$ were married, and $44 \%$ of participants achieved post-graduate degrees. Forty-two percent of the entire sample was born in the U.S.
Table 3. Demographic Data of LA Sample and NY Metropolitan Sample

\begin{tabular}{|c|c|c|c|}
\hline Category & LA Sample $(n=203)$ & \multicolumn{2}{|c|}{ NY Sample (n=447) } \\
\hline & Male & $32.0 \%$ & $35.4 \%$ \\
\hline Gender, \% & Female & $68.0 \%$ & $64.6 \%$ \\
\hline & Mean & 38.07 & 35.57 \\
\hline Age, years & Range & 18 to 60 & 18 to 60 \\
\hline \multirow[t]{3}{*}{ Age subgroup, \% } & $18-29$ years & $29.1 \%$ & $46.3 \%$ \\
\hline & $30-40$ years & $23.2 \%$ & $19.7 \%$ \\
\hline & $41-60$ years & $40.9 \%$ & $31.3 \%$ \\
\hline \multirow{4}{*}{$\begin{array}{c}\text { BMI, \% } \\
\text { (General population } \\
\text { standards) }\end{array}$} & Underweight & $7.4 \%$ & $5.8 \%$ \\
\hline & Normal weight & $62.1 \%$ & $68.5 \%$ \\
\hline & Overweight & $18.7 \%$ & $16.6 \%$ \\
\hline & Obese & $3.9 \%$ & $4.7 \%$ \\
\hline \multirow{5}{*}{ Income, \$, \% } & Under 20,000 & $26.6 \%$ & $39.3 \%$ \\
\hline & 20,000-39,999 & $14.3 \%$ & $13.1 \%$ \\
\hline & 40,000-59,999 & $10.8 \%$ & $17.8 \%$ \\
\hline & 60,000-79,999 & $5.9 \%$ & $12.6 \%$ \\
\hline & 80,000 and above & $29.6 \%$ & $16.9 \%$ \\
\hline \multirow{6}{*}{ Education, \% } & $\begin{array}{l}\text { Elementary school or } \\
\text { less }\end{array}$ & $0.5 \%$ & $0.7 \%$ \\
\hline & Some high school & $0.5 \%$ & $2.9 \%$ \\
\hline & High school graduate & $4.4 \%$ & $11.5 \%$ \\
\hline & Some college & $15.3 \%$ & $19.9 \%$ \\
\hline & College graduate & $29.6 \%$ & $37.5 \%$ \\
\hline & Post graduate & $44.3 \%$ & $27.5 \%$ \\
\hline \multirow{4}{*}{ Marital status, \% } & Married & $49.3 \%$ & $45.9 \%$ \\
\hline & Divorced & $3.9 \%$ & $2.0 \%$ \\
\hline & Separated & $1.0 \%$ & $0.7 \%$ \\
\hline & Never married & $37.4 \%$ & $50.2 \%$ \\
\hline \multirow{4}{*}{$\begin{array}{l}\text { Physical activity } \\
\text { level, \% }\end{array}$} & Sedentary & $24.6 \%$ & $25.2 \%$ \\
\hline & Light activity & $26.6 \%$ & $25.2 \%$ \\
\hline & Moderate activity & $38.4 \%$ & $46.0 \%$ \\
\hline & Heavy activity & $2.5 \%$ & $3.6 \%$ \\
\hline
\end{tabular}

The average BMI of the LA participants was $22.8 \pm$ 3.58. Based on standard BMI indices, $7 \%$ of the participants were underweight, $62 \%$ normal weight, $19 \%$ overweight and 4\% obese. Forty-five percent of male respondents were overweight or obese, as compared with $16 \%$ of the female respondents. Among participants with post-graduate degrees, $25 \%$ were overweight or obese, in contrast with $11 \%$ with high school diplomas. However, using the WHO standards for Asian populations, 29\% of the entire LA sample were overweight and $9 \%$ were obese.

\subsection{Obesity Risk Reduction Behaviors}

Comparison of data measuring obesity risk reduction behavior between LA and NY samples indicated significant differences related to eating and physical activity (Table 4). LA respondents reported higher frequency of limiting portion sizes $(\mathrm{p}<0.01)$, using steamed instead of fried foods $(\mathrm{p}<0.05)$, eating at least 2 servings of fruits per day $(\mathrm{p}<0.05)$, eating healthful snacks and whole grains $(\mathrm{p}<0.05)$, limiting intake of high calorie beverages $(\mathrm{p}<0.01)$, and engaging in regular exercise including physical active leisure activities $(\mathrm{p}<0.05)$. There were no significant differences in the psychosocial context of obesity risk reduction behaviors. 
Table 4. T-Test Comparisons on Obesity Risk Reduction Behaviors Between LA and NY Samples

\begin{tabular}{|c|c|c|c|c|c|}
\hline Category & LA Mean & SD & NY Mean & SD & Sig. (2-tailed) \\
\hline Eating Context & & & & & \\
\hline $\begin{array}{l}\text { Ate home-cooked meals instead of } \\
\text { restaurant-prepared meals }\end{array}$ & 3.11 & 0.87 & 3.06 & 0.88 & 0.496 \\
\hline Limited my portion sizes of foods & 2.64 & 0.99 & 2.37 & 0.93 & $0.001 * *$ \\
\hline $\begin{array}{l}\text { Used portion size control methods to } \\
\text { help decide how much to eat }\end{array}$ & 2.09 & 1.05 & 2.1 & 1.00 & 0.914 \\
\hline $\begin{array}{l}\text { Followed traditional healthful Chinese } \\
\text { food patterns }\end{array}$ & 2.83 & 1.01 & 2.81 & 0.99 & 0.833 \\
\hline \multicolumn{6}{|l|}{ Food Context } \\
\hline Ate steamed foods instead of fried foods & 2.79 & 0.94 & 2.62 & 0.91 & $0.026^{*}$ \\
\hline $\begin{array}{l}\text { Used small amounts of oils or fat when } \\
\text { preparing or cooking foods }\end{array}$ & 3.00 & 0.97 & 2.96 & 0.97 & 0.544 \\
\hline $\begin{array}{c}\text { Ate at least } 3,1 \text {-oz servings of whole } \\
\text { grains per day }\end{array}$ & 2.74 & 0.85 & 2.74 & 0.95 & 0.940 \\
\hline Ate at least 2 servings of fruit each day & 2.75 & 0.98 & 2.56 & 0.96 & $0.021 *$ \\
\hline $\begin{array}{c}\text { Ate at least } 3 \text { 1-oz servings of whole } \\
\text { grains per day }\end{array}$ & 2.75 & 0.93 & 2.56 & 0.99 & $0.023^{*}$ \\
\hline $\begin{array}{l}\text { Made healthier choices at fast food } \\
\text { restaurants }\end{array}$ & 2.49 & 1.10 & 2.4 & 1.04 & 0.281 \\
\hline Ate healthful snacks & 2.93 & 0.94 & 2.64 & 0.93 & $0.000 * * *$ \\
\hline Ate healthful pre-packaged foods & 2.24 & 1.04 & 2.25 & 0.99 & 0.847 \\
\hline Limited intake of high-calorie beverages & 3.25 & 0.99 & 2.91 & 1.07 & $0.000 * * *$ \\
\hline Psychological & & & & & \\
\hline $\begin{array}{l}\text { Took time to decrease the amount of } \\
\text { stress I feel }\end{array}$ & 2.71 & 0.93 & 2.59 & 0.89 & 0.088 \\
\hline $\begin{array}{l}\text { Took time to relax and improve my } \\
\text { emotional well-being }\end{array}$ & 2.87 & 0.94 & 2.73 & 0.91 & 0.075 \\
\hline \multicolumn{6}{|l|}{ Knowledge Awareness Context } \\
\hline Monitored my weight & 2.56 & 1.08 & 2.55 & 1.05 & 0.940 \\
\hline $\begin{array}{l}\text { Learned about obesity risk and } \\
\text { prevention }\end{array}$ & 1.92 & 1.07 & 2.04 & 1.04 & 0.190 \\
\hline Physical Activity Context & & & & & \\
\hline $\begin{array}{c}\text { Engaged in at least } 1 \text { physically active } \\
\text { leisure activity }\end{array}$ & 2.70 & 1.08 & 2.47 & 1.09 & $0.011^{*}$ \\
\hline $\begin{array}{c}\text { Exercised at least } 30 \text { minutes, on 3-5 } \\
\text { days/week }\end{array}$ & 2.65 & 1.14 & 2.41 & 1.09 & $0.011^{*}$ \\
\hline $\begin{array}{l}\quad \text { Average of all Behaviors } \\
* \quad \mathrm{p}<0.05 \text { level } \\
* * \quad \mathrm{p}<0.01 \text { level } \\
* * * \quad \mathrm{p}<0.001 \text { level }\end{array}$ & 2.69 & 0.49 & 2.57 & 0.98 & \\
\hline
\end{tabular}

\subsection{Psychosocial Variables Explaining Obesity Risk Reduction Behaviors}

Using the LA sample, multiple regression analyses demonstrated that psychosocial variables from the TPB and HBM explained $39 \%$ of the total variance of the overall obesity risk reduction behaviors (Table 5). Self-efficacy $(\beta=0.48)$ and attitude $(\beta=0.24)$ emerged as important predictors of the obesity risk reduction behaviors. A variance of $46.9 \%$ was reported in predicting behavioral intention in which self-efficacy $(\beta=0.49)$, motivation to comply $(\beta=0.25)$, and perceived barriers $(\beta=-0.18)$ were significant contributors. 
Table 5. Regression Analysis of Theory of Planned Behavior and Health Belief Model Variables in Predicting Obesity Risk Reduction Behaviors in LA \& NY Samples

\begin{tabular}{|c|c|c|c|c|c|c|}
\hline The Predicted & Significant Predictors & $\mathbf{R}^{2}(\%)$ & $\beta$ & b & SE of $B$ & $\mathbf{p}$ \\
\hline \multirow{3}{*}{$\begin{array}{l}\text { Obesity Risk Reduction } \\
\text { Behaviors in LA Sample }\end{array}$} & Self-efficacy & & 0.480 & 0.380 & 0.077 & 0.00 \\
\hline & Attitude & $38.7 \%$ & 0.235 & 0.123 & 0.051 & 0.018 \\
\hline & Self-efficacy & $47.3 \%$ & 0.426 & 0.343 & 0.044 & 0.000 \\
\hline \multirow{2}{*}{$\begin{array}{l}\text { Obesity Risk Reduction } \\
\text { Behaviors in NY Sample }\end{array}$} & Intention & & 0.272 & 0.197 & 0.042 & 0.000 \\
\hline & Attitude & & 0.131 & 0.123 & 0.050 & 0.014 \\
\hline
\end{tabular}

In the NY sample, $47 \%$ of the variance of behavior was accounted for by self-efficacy $(\beta=0.43)$, intention $(\beta=0.27)$, and attitude $(\beta=0.13)$. When behavioral intention was designated as the dependent variable, a variance of $41 \%$ was reported in which self-efficacy $(\beta=0.37)$, attitude $(\beta=0.33)$, and perceived barriers $(\beta=-0.16)$ were significant contributors.

\subsection{T-Test Comparisons}

T-test comparisons of demographic and psychosocial factors between the LA and NY metropolitan samples indicated a number of key findings. Mean LA and NY sample ages were comparable, 38.1 and 35.6 respectively; however, the LA sample had more individuals in the oldest category and the NY sample had more in the youngest group. The LA sample as compared to the NY achieved a higher level of education $(\mathrm{p}<0.01)$ and average annual income $(\mathrm{p}<0.01)$. BMI of the LA and NY samples did not indicate significant differences. Combined data of both regions indicated a significant BMI difference regarding country of origin. Mean BMI levels were higher for U.S.-born as compared with foreign-born individuals (BMI=23.2 vs. $B M I=22.6, \mathrm{p}<0.05)$.

Regarding psychosocial variables, the LA sample indicated more favorable attitudes in adopting obesity prevention behaviors (5.69 vs. 4.22 , scale of $1-7, \mathrm{p}<0.01$ ) and stronger intentions to engage in the behaviors (4.76 vs. 3.69, scale of $1-7, \mathrm{p}<0.01$ ) than their NY counterparts. However, the NY sample perceived more barriers to performing health behaviors (3.30 vs. 3.14, scale of $1-5$, $\mathrm{p}<0.01$ ) and more negative influences of the physical environment on their ability to make healthy food choices (3.25 vs, 2.93, scale of $1-5, \mathrm{p}<0.01$ ).

\section{Discussion}

This study reflects an innovative West and East Coast analysis of obesity-related beliefs and behaviors among Chinese Americans, thus filling an important gap in the literature. This multi-state approach provides a critical comparative analysis in both contrasting and confirming findings related to dietary practices and key psychosocial determinants of obesity risk reduction behaviors.

In general, the sample of Chinese Americans from LA County engaged in a higher frequency of behaviors related to healthy eating and physical activity as compared with the NY sample. Such behaviors included limiting portion sizes of foods, consuming healthful snacks and recommended daily servings of fruits and whole grains, replacing fried foods with steamed alternatives, limiting intake of high caloric beverages, and engaging in recommended frequency of physical activity per week.

Regression analyses pointed to the significant contributors of self-efficacy, attitude, and intention in explaining obesity prevention behaviors in both the LA and NY participants. In our study of LA participants, selfefficacy and attitude were salient contributors of behavior for the entire sample. However, intention emerged as an additional contributing factor in predicting behavior in the NY participants. These findings from the LA sample provides confirmatory data, as compared with the NY sample, in the importance of self-efficacy, intention, and attitude in contributing to obesity risk reduction behaviors among Chinese Americans [19]. Similarly, Liou and Contento's study of dietary fat reduction behaviors in Chinese Americans identified the importance of selfefficacy in predicting behavioral outcomes [24]. Lo et al. examined associations between HBM constructs including self-efficacy and health promoting behaviors in Chinese individuals living in Hong Kong, China [25]. Health promoting behaviors were set as the dependent variable in the regression analysis. Results included that HBM factors accounted for $11 \%$ of the total variance in healthpromoting behaviors and self-efficacy explained an additional $31 \%$ of variance in exercise behavior, and $13 \%$ of variance in diet management behavior. Self-efficacy and perceived barriers made independent contributions to health-promoting behavior among people with or at high risk of metabolic syndrome.

In our study, attitude was the major factor contributing to intention to engage in obesity risk reduction behaviors among the NY participants. Prior studies conducted with Caucasian Americans have also shown the predominant influence of attitudes in the prediction of behavioral intention [26,27]. American culture emphasizes individualism and the freedom to express one's predispositions toward behavioral patterns. We postulate that this strong internalization of personal predispositions outweighs the influence of other psychosocial factors such as subjective norm. Thus, the results of the regression analysis for the NY group depicted a smaller variance for subjective norm than the LA group. However, in the LA sample, motivation to comply to the wishes to important others did emerge as a significant predictor of behavioral intention.

For both samples, perceived barriers of healthy eating emerged as significant predictors of behavioral intention. Participants in both coastal regions indicated that their physical and social environments provided an abundance of unhealthy food choices, and they identified readily available fast food restaurants as a major impediment to weight control. Similar barriers to healthy eating were identified in Harrison et al.'s focus group interviews with 
Asian Americans in the identification of fast food as convenient, contributing to the adoption of their eating habits [28].

Our study findings of weight comparisons of males and females corresponded to California government data. The LA County Health Survey indicated that $55 \%$ of adults of all racial groups were overweight or obese and obesity rates tended to be higher for males than females [29]. The Asian data of the California Health Interview Survey (2001) included Asian American and Pacific Islanders (AAPI). The data showed that $42 \%$ of men and $22 \%$ of women were overweight or obese. Our study also confirmed that males were more likely to be overweight or obese than females. Our percentages were not as high as California's government data, which indicated high propensity for obesity among Asians [30]. However, their data included a variety of Asian groups.

In our study, U.S.-born participants tended to possess higher BMI levels than foreign-born individuals. This finding is consistent with the published literature stating that U.S.-born Asians are more likely to be overweight and obese than foreign-born Asians [7]. Furthermore, acculturation to a Western diet and lifestyle increases obesity risk among various immigrant groups [31].

Notable strengths in our study included the recruitment of participants from opposite coasts of the U.S., reflecting diverse sociocultural, religious, and educational backgrounds. A multi-state comparative approach provided further validation of psychosocial determinants of obesity risk reduction behaviors. Our LA sample was similar with the U.S. Census data on Chinese American demographics in LA County in terms of the percentage of educational attainment (associate/bachelor's degrees), but our sample reflected a higher percent of U.S.-born individuals as compared with the reported census ( $42 \%$ vs. $28 \%$ ).

Study limitations point to a limited ability to generalize the findings to the entire Chinese American population due to the attainment of a non-randomized, convenience sample. Subjects who volunteered to participate may be more health-conscious than non-participants, thus affecting the reporting of lifestyle behaviors. Social desirability bias may be evident in the over-reporting of health behaviors and the under-reporting of actual weight, especially in female participants due to societal pressures to be thin. The researchers postulated that the percentages of overweight and obese were likely to be higher since actual weight of participants were not measured.

\section{Conclusions}

Nutrition educators and health professionals working with Chinese Americans living in Los Angeles need to assess their confidence and ability to engage in obesity risk reduction behaviors such as portion size control and consuming nutrient-dense foods in lieu of high-fat and high-sugary options. In promoting favorable attitudes toward these health behaviors, minimizing perceptions of barriers such as cost and inconvenience can be beneficial. Behavioral intentions can be heightened by self-efficacy, knowing how to purchase and prepare healthy food options and motivation to comply with the dietary recommendations given by positive social referents.
Future studies can elucidate the cognitive processes of adopting obesity risk reduction behaviors in terms of mapping out the influences of beliefs and attitudes on behavior change in specific regions and cities in the U.S. Exploring the impact of the physical and social environments on these health behaviors need further investigation. A longitudinal study design can be instrumental in determining the stability of these psychosocial and environmental factors in explaining obesity risk reduction behaviors, especially in immigrant and minority population groups to ascertain changes due to acculturation effects.

\section{References}

[1] World Health Organization. 10 Facts on obesity. World Health Organization website.

http://www.who.int/features/factfiles/obesity/en/. Published 2017.

[2] Office of Disease Prevention and Health Promotion. Nutrition, physical activity, and obesity: Latest data. https://www.healthypeople.gov/2020/leading-healthindicators/2020-lhi-topics/nutrition-physical-activity-andobesity/data\#NWS-9.

[3] Lv N, Brown JL. Chinese American family food systems: Impact of Western Influences. J Nutr Educ Behav. 2010; 42(2): 106-114.

[4] Lutsey PL et al. Association of acculturation and socioeconomic status with subclinical cardiovascular disease in the Multi-Ethnic Study of Atherosclerosis. Am J Public Health. 2008; 98(11): 1963-1970.

[5] Demory-Luce D, Morales M, Nicklas T. Acculturation, weight status, and eating habits among Chinese-American preschool children and their primary caregivers: A pilot study. Nutr Res. 2005; 25(3): 213-224.

[6] Sing GK, Ling SC. Dramatic increases in obesity and overweight prevalence among Asian subgroups in the United States, 1992-2011. ISRN Preventative Medicine. 898691. 2013.

[7] Wang S, Quan J, Kanaya AM, Fernandez A. Asian Americans and obesity in California: A protective effect of biculturalism. $J$ Immigr Minor Health. 2011; 12(2): 276-283.

[8] Lindberg NM, Stevens VJ. Immigration and weight gain: Mexican-American women's perspectives. J Immigr Minor Health 2013; 13(1): 155-160.

[9] Ahima RS, \& Lazar MS. Physiology: the health risk of obesitybetter metrics imperative. Science. 2013; 341: 856-858.

[10] Wong RJ, Ahmed A. Obesity and non-alcoholic fatty liver disease: Disparate associations among Asian populations. World J Hepatol. 2014; 6(5): 263-273.

[11] Wei H et al. Greater abdominal fat accumulation is associated with higher metabolic risk in Chinese than in white people: an ethnicity study. PLoS ONE. 2013; 8(3): 58688.

[12] Hsu WC et al. BMI cut points to identify at-risk Asian Americans for type 2 diabetes screening. Diabetes Care. 2015; 38(1): 150-158.

[13] World Health Organization (WHO) Expert Consultation. Appropriate body-mass index for Asian populations and its implications for policy and intervention strategies. Lancet. 2004; 363: 157-63.

[14] United States Census Bureau. (2014). Projections of the size and composition of the U.S. population: 2014 to 2060. S. L. Colby \& J. M. Ortman (Auths). (Current Population Reports). Retrieved from https://www.cencus.gov/library/publications/2015/demo/p251143.html

[15] Asian Americans Advancing Justice - Los Angeles. A community of contrasts: Asian Americans, Native Hawaiians and Pacific Islanders in Los Angeles County. Asian Americans Advancing Justice - Los Angeles. Los Angeles County, CA.

[16] Rosenstock IM, Kirscht JP. The health belief model and personal health behavior. Health Education Monographs. 1974; 2(4): 470-473.

[17] Bandura A. Foundations of thought and action: A social cognitive theory. Englewood Cliffs: Prentice-Hall; 1986. 
[18] Ajzen I. The theory of planned behavior. Organizational Behavior Human Decision Process. 1991; 50(2): 179-211.

[19] Liou D, Bauer KD, Bai Y. Psychosocial variables and obesity risk reduction behaviors in Chinese Americans. Ecol Food Nutr. 2011; 50(6): 486-505.

[20] Liou D, Bauer KD, Bai Y. A cross-sectional analysis of obesity risk reduction behaviors and demographic factors among Chinese Americans. J Obes Weight Loss Medicat. 2016; 2: 016.

[21] Bes-Rastrollo $\mathrm{M}$ et al. A prospective study of eating away-fromhome meals and weight gain in a Mediterranean population: the SUN (Seguimiento Universidad de Navarra) Cohort. Public Health Nutr. 2010; 13(9): 1356-1363.

[22] Smith KJ, McNaughton SA, Gall SL, Blizzard L, Dwyer T, Venn AJ. Takeaway food consumption and its associations with diet quality and abdominal obesity: A cross-sectional study of young adults. Int J Behav Nutr Phy. 2009; 6(29): 1-13.

[23] Kline P. An easy guide to factor analysis. London: Routledge; 1994.

[24] Liou D, Contento I. Usefulness of psychosocial theory variables in explaining fat-related dietary behavior in Chinese Americans: association with degree of acculturation. Journal of Nutrition Education 2001; 33(6): 322-331.
[25] Lo SWS, Chair SY, Lee FK. Factors associated with healthpromoting behavior of people with or at high risk of metabolic syndrome: Based on the health belief model. Applied Nursing Research 2015; 28(2): 197-201.

[26] Shepherd R, Stockley L. Nutrition knowledge, attitudes, and fat consumption. Journal of the American Dietetic Association 1987; 87: 5: 615-9.

[27] Tuorila H. Selection of milks with varying fat contents and related overall liking, attitudes, norms, and intentions. Appetite 1987; 8: 1: $1-14$.

[28] Harrison G, Kagawa-Singer M, Foerster SB, et al. Seizing the moment: California's opportunity to prevent nutrition-related health disparities in low-income Asian American populations. Cancer 2005; 104, S12: 2962-8.

[29] Los Angeles County Department of Health Services. Obesity on the rise. Los Angeles, CA, 2003.

[30] Staimez LR, Weber MB, Narayan KMV, Oza-Frank R. A systematic review of overweight, obesity, and type 2 diabetes among Asian American subgroups. Curr Diabetes Rev. 2013; 9(4) 312-331.

[31] Oakkar EE et al. Longitudinal study of acculturation and BMI change among Asian American men. Prev Med. 2015; 73: 15-21. 